\title{
Ethephon no raleio de tangerinas 'Ponkan'
}

\author{
Ethephon in 'Ponkan' mandarin thinning
}

\begin{abstract}
José Darlan Ramos ${ }^{\mathrm{I} *}$ Maria do Céu Monteiro da Cruz ${ }^{\mathrm{I}}$ Moacir Pasqual $^{\mathrm{I}}$ Oscar Mariano Hafle ${ }^{\mathrm{I}}$ Patrícia de Siqueira Ramos ${ }^{\mathrm{II}}$ Erick Pretti Rossi ${ }^{\mathrm{I}}$
\end{abstract}

\section{- NOTA -}

\section{RESUMO}

Este trabalho foi realizado com o objetivo de avaliar o efeito do ethephon sobre o raleio químico das frutas de tangerineira "Ponkan". O ethephon foi aplicado nas tangerineiras em dois estádios de desenvolvimento das frutas: um e dois $\mathrm{cm}$ de diâmetro, sendo testadas quatro concentrações: 0,0; 100; 200 e $400 \mathrm{mg} \mathrm{L}^{-1}$. Foram utilizadas três plantas úteis por parcela, com quatro repetições, perfazendo um total de 96 plantas. A qualidade das frutas foi avaliada a prtir das características: massa fresca da fruta, diâmetro transversal e longitudinal da fruta, número de gomos, número de sementes, sólidos solúveis ( ${ }^{\circ}$ Brix), pH do suco, acidez titulável, relação sólidos solúveis/acidez (ratio) e produção. A aplicação de ethephon na concentração de $400 \mathrm{mg} \mathrm{L}^{-1}$, no estádio de desenvolvimento de dois $\mathrm{cm}$ para o raleio químico da tangerineira "Ponkan" proporciona o melhor resultado com maior massa fresca das frutas, quando comparado com o resultado da não aplicação do produto.

Palavras-chave: Citrus reticulata, raleio químico, etileno, ácido 2-cloroetil fosfônico.

\section{ABSTRACT}

The aim of this research was to evaluate the ethephon effect on chemical thinning of the mandarin fruits 'Ponkan'. The ethephon was applied in the plants of mandarin in two development stages of the fruits: one and two $\mathrm{cm}$ of diameter, being tested four concentrations, 0,0; 100; 200 and $400 \mathrm{mg} \mathrm{L}^{-1}$. Three experimental units with four repetitions were used, in a total of 96 plants. The quality of the fruits was evaluated with the characteristics of average weight of the fruit, transversal and longitudinal diameter of the fruit, corners and seed numbers, soluble solids ( $\left.{ }^{\circ} \mathrm{Brix}\right) ; \mathrm{pH}$ of the juice, titratable acidity, ratio between ${ }^{\circ}$ Brix and acidity (ratio) and production. The ethephon application for the chemical thinning of the mandarin 'Ponkan' at $400 \mathrm{mg} \mathrm{L}^{-1}$ concentration in the development stage of two $\mathrm{cm}$ provide the best result with increase in weight of the fruits when compared to the non-chemical application.

Key words: Citrus reticulata, chemical thinning, ethylene, 2chloroethylphosphonic acid.

A “Ponkan” (Citrus reticulata Blanco) é uma das tangerinas mais populares e apreciadas para consumo in natura, assim como para o processamento industrial. Suas características internas e externas devem ser consideradas, visando uma melhor aparência e qualidade das frutas. Dentre as características externas, o tamanho da fruta é um dos principais fatores de qualidade observados pelos consumidores de frutas frescas (GUARDIOLA, 1992).

No caso da tangerineira "Ponkan”, o fato de ela apresentar alternância de produção, com produção excessiva em um ano e pouca no outro, resulta em frutas pequenas e de baixa qualidade, as quais alcançam menores preços no mercado. Uma alternativa para minimizar o problema de alternância e melhorar a qualidade de frutas é a realização de raleio das frutas em anos de alta produção, que pode ser realizado manual ou quimicamente.

O raleio químico vem sendo muito utilizado por mostrar-se mais eficiente, em comparação com o raleio manual (SHARMA\& \&WASTHI, 1990). Em tangerineira

'Departamento de Agricultura, Universidade Federal de Lavras (UFLA), CP 3037, 37200-000, Lavras, MG, Brasil. E-mail: darlan@ufla.br. *Autor para correspondência. 
“Ponkan”, a aplicação de ethephon mostrou-se o agente mais eficaz para o desbaste das frutas quando aplicado no final de novembro, em comparação com outros fitorreguladores, como Ácido naftalenacético, Figaron, Carbaril e raleio manual (SANTOS \& CASTRO, 2001).

O raleio das frutas provocado pela aplicação de fitorreguladores favorece aumento no seu tamanho, pois modifica as relações nutricionais endógenas das plantas, assim como a sua distribuição (AGUSTÍ et al., 1995). Para esses autores, essa prática tem se mostrado muito eficaz para produzir frutas de alta qualidade e reduzir a alternância de colheitas em vários países, como Japão, Austrália e EUA.

Dentre as substâncias utilizadas para raleio de frutas, merecem destaque o ácido 2-cloroetil fosfônico (ethephon). Na literatura, há vários trabalhos que comprovaram sua eficiência como promotora da queda de frutas cítricas (CASTRO, 2001; SERCILOTO \& CASTRO, 2001, SERCILOTO et al., 2003).

O ethephon é um fitorregulador que libera etileno em contato com o tecido vegetal. Ele tem sido aplicado visando à prática do raleio de frutas (SANCHES, 2000). Seus efeitos, no entanto, não são específicos, e, dependendo das condições climáticas, o momento da aplicação é fundamental, pois deve-se considerar que a utilização do fitorregulador pode afetar uma característica diferente do objetivo proposto (GUARDIOLA \& GARCÍA-LUIS, 2000).

A melhor época para aplicação do ethephon com objetivo de raleio das frutas varia em função das condições climáticas de cada localidade. De acordo com SUZUKI et al. (1990) e ORTOLA et al. (1998), a época adequada para realizar a aplicação dos raleantes químicos é no período pós-florada, cerca de 30 a 40 dias após o florescimento, quando os frutos se encontram entre 1,5 e 2,0cm de diâmetro.

Existem vários trabalhos com resultados da aplicação de ethephon que comprovam seu efeito sobre o raleio de frutas em várias cultivares de citros. No entanto, as informações científicas de seu uso em tangerineira "Ponkan” são variáveis, sendo necessário conhecer e quantificar a contribuição advinda da aplicação desse fitorregulador na qualidade das frutas e regularização da produção. Nesse contexto, este trabalho foi realizado com o objetivo de avaliar o efeito do ethephon sobre o raleio químico das frutas de tangerineira "Ponkan".

O trabalho foi conduzido no período de setembro 2003 a agosto de 2004, em pomar comercial de tangerineira "Ponkan” localizado às margens da Rodovia BR 381, Km 607, no município de Perdões, sul de Minas Gerais. A altitude média da região é de 900 metros, e o tipo climático é $\mathrm{Cwb}$, segundo a classificação de Koppen, caracterizado com verões quentes e úmidos e invernos secos e frios.

Foram utilizadas plantas de tangerineira "Ponkan" enxertadas sobre limoeiro "Cravo", com seis anos de idade, conduzidas sem irrigação, no espaçamento de 6,0 metros entre linhas e 3,0 metros entre plantas.

Os tratamentos utilizados foram quatro concentrações de ethephon: 0, 100, 200 e 400mg L-1, aplicadas em dois estádios de desenvolvimento das frutas (um e dois cm de diâmetro). O esquema experimental utilizado foi o fatorial $2 \times 4$, no delineamento de blocos casualizados, com quatro repetições e três plantas por parcela, perfazendo o total de 96 plantas.

As plantas foram pulverizadas com o produto comercial Ethrel 720, da Aventis CropScience ISA, cuja composição é de $72 \%$ do ácido 2-cloroetil fosfônico e 57,5\% de ingredientes inertes. Foram utilizados, aproximadamente, três litros de solução por planta, em toda a extensão da copa. Esse volume foi previamente determinado mediante teste em branco, aplicando apenas água, obtendo-se molhamento homogêneo da cobertura foliar e evitando o escorrimento e a deriva do produto.

As plantas foram pulverizadas em duas épocas, quando as frutas apresentavam o diâmetro de um $\mathrm{cm}$ e de dois $\mathrm{cm}$, mediante amostragens realizadas em quatro ramos por planta, considerando que, pelo menos, três dos ramos amostrados atingissem esse ponto de desenvolvimento.

Aos seis meses após a aplicação dos tratamentos, foram colhidas cinco frutas por planta de cada tratamento na parte mediana da planta, considerando os quatro quadrantes para as análises das características: massa fresca (g), utilizando-se balança Filizolla de um kg; diâmetro transversal e longitudinal $(\mathrm{cm})$ com paquímetro; contagem do número de gomos; número de sementes; sólidos solúveis ( ${ }^{\circ}$ Brix) com refratômetro digital de bancada modelo SR400; pH com peagâmetro; acidez titulável mediante titulação com $\mathrm{NaOH} 0,1 \mathrm{~N}$, sendo utilizandos $5 \mathrm{~mL}$ por amostra de fenolftaleína como indicador e ratio, pela relação sólidos solúveis/acidez.

Para a análise da produção, aos sete meses após a aplicação dos tratamentos, foram colhidas todas as frutas de cada planta de todas as parcelas, separando-as por caixas de 22,0kg por tratamento.

Os dados coletados foram submetidos à análise de variância utilizando-se o software Sistemas deAnálises de Variância para dados Balanceados - Sisvar (FERREIRA, 2000), a regressão polinomial encolhendo os modelos com base na significância dos coeficientes de regressão. As médias foram comparadas pelo teste de Tukey, a $5 \%$ de probabilidade de erro. 
Houve interação entre as concentrações de ethephon e o estádio de desenvolvimento no momento da aplicação para as variáveis, massa das frutas, acidez titulável e ratio. Também houve efeito da aplicação das diferentes concentrações de ethephon para o diâmetro transversal das frutas aplicado no estádio de dois $\mathrm{cm}$.

Foi observado incremento de $24,26 \%$ na massa fresca das frutas, no estádio de dois $\mathrm{cm}$ (Figura 1A), com aumento da concentração de 0 para $400 \mathrm{mg} \mathrm{L}^{-1}$ de ethephon. No entanto, nas plantas que foram pulverizadas quando as frutas estavam no estádio de um cm, verificou-se que a massa fresca das frutas não diferiu entre as concentrações de ethephon aplicadas, sendo observados os menores valores (Tabela 1).

O aumento da massa fresca das frutas nas plantas que receberam a maior concentração de ethephon, quando estavam no estádio de dois cm, devese à ação do ethephon no raleio das frutas. Resultados semelhantes foram obtidos por SERCILOTO et al. (2003), que observaram incremento de $17,3 \%$ na massa das frutas de tangor 'Murcote' com a aplicação de ethephon. Com relação ao tamanho das frutas, avaliado pelos diâmetros transversal e longitudinal, foi observado aumento do diâmetro transversal das frutas de $9,57 \%$ nas plantas que foram pulverizadas com a concentração de 400mg L-1 de ethephon, no estádio de dois cm (Figura 1B), diferindo das frutas do estádio de um $\mathrm{cm}$, que não apresentaram diferenças entre as concentrações de ethephon aplicadas. Para o diâmetro longitudinal, não houve diferença significativa nas frutas das plantas tratadas com as diferentes concentrações em ambos os estádios de desenvolvimento (Tabela1).

Isso possivelmente tenha ocorrido pelo raleio das frutas nas plantas que receberam a aplicação do ethephon, aumentando a disponibilidade de metabólitos para as frutas remanescentes, mediante a redução do número de frutas por planta e, portanto, da competição entre os órgãos em desenvolvimento ou

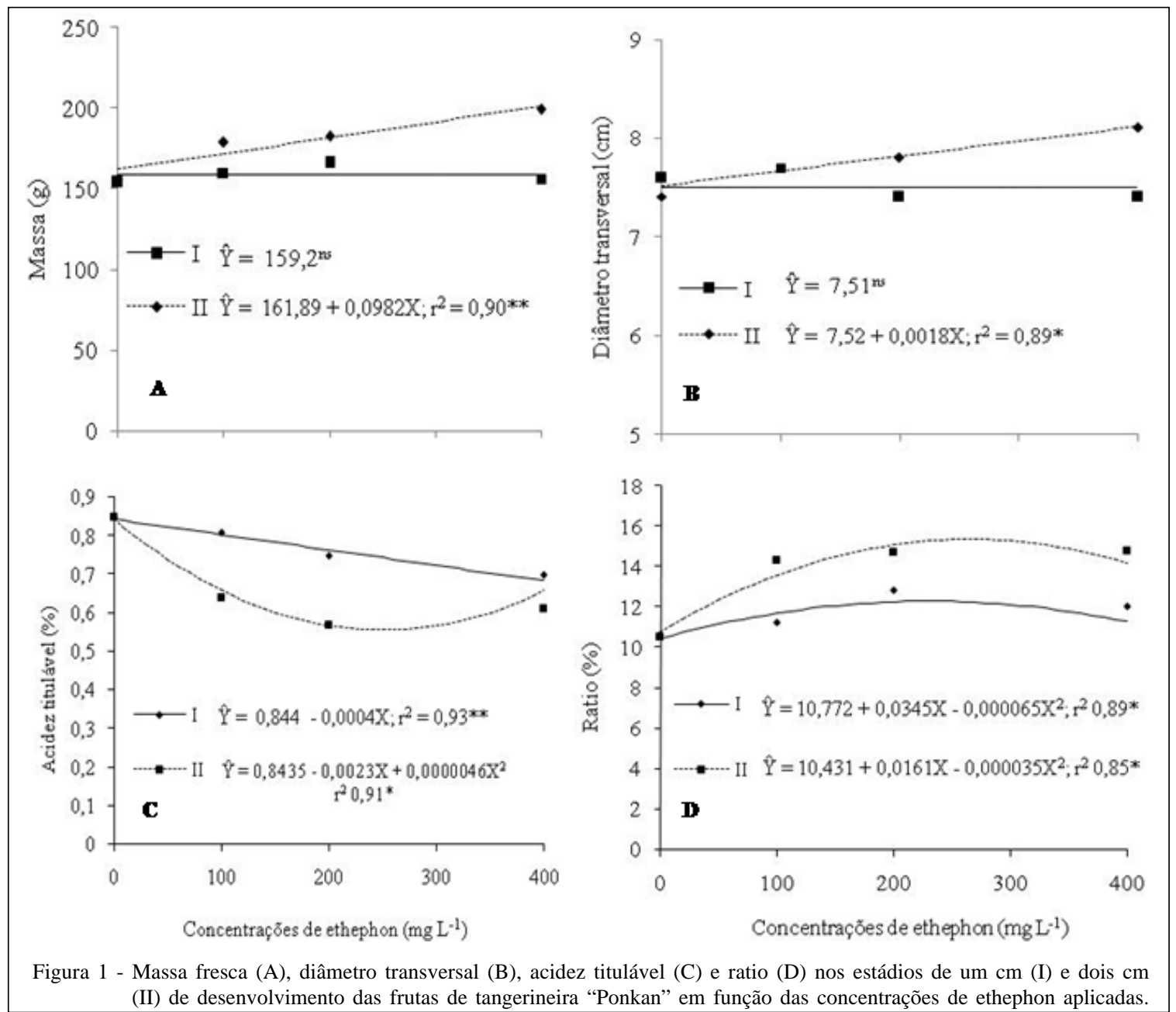

Ciência Rural, v.39, n.1, jan-fev, 2009. 
Tabela 1 - Médias das características físico-químicas avaliadas nas frutas de tangerineira "Ponkan”, pulverizadas com as diferentes concentrações de ethephon, nos estádios de um cm (I) e dois cm (II) de desenvolvimento das frutas.

\begin{tabular}{|c|c|c|c|c|c|c|c|c|c|c|}
\hline \multirow[t]{2}{*}{$\begin{array}{l}\text { Concentrações de } \\
\text { ethephon }\left(\mathrm{mg} \mathrm{L}^{-1}\right)\end{array}$} & \multicolumn{2}{|c|}{ massa (g) } & \multicolumn{2}{|c|}{$\varnothing$ transversal $(\mathrm{cm})$} & \multicolumn{2}{|c|}{$\varnothing$ longitudinal $(\mathrm{cm})$} & \multicolumn{2}{|c|}{ № gomos } & \multicolumn{2}{|c|}{ №- sementes } \\
\hline & I & II & I & II & I & II & I & II & I & II \\
\hline 0 & 153,8 a & 156,0 a & 7,6 a & $7,4 \mathrm{a}$ & 7,04 & 7,0 & 10,0 & 9,9 & 10,0 & 9,9 \\
\hline 100 & $159,9 \mathrm{~b}$ & 178,5 a & 7,7 a & 7,8 a & 7,14 & 7,4 & 10,2 & 10,0 & 10,2 & 10,0 \\
\hline 200 & $166,7 \mathrm{~b}$ & $182,4 \mathrm{a}$ & $7,4 \mathrm{a}$ & $7,8 \mathrm{a}$ & 7,07 & 7,3 & 10,2 & 10,1 & 10,2 & 10,1 \\
\hline 400 & $156,6 \mathrm{~b}$ & 198,9 a & $7,4 \mathrm{~b}$ & $8,1 \mathrm{a}$ & 6,94 & 7,1 & 10,0 & 10,3 & 10,0 & 10,3 \\
\hline CV (\%) & & & & & & & & & & \\
\hline \multirow[t]{2}{*}{$\begin{array}{l}\text { Concentrações de } \\
\text { ethephon }\left(\mathrm{mg} \mathrm{L}^{-1}\right)\end{array}$} & \multicolumn{2}{|c|}{$\begin{array}{c}\text { Produção caixa } 22 \\
\text { kg }\end{array}$} & \multicolumn{2}{|c|}{$\mathrm{pH}$} & \multicolumn{2}{|c|}{ Acidez (\%) } & \multicolumn{2}{|c|}{${ }^{\circ}$ Brix (\%) } & \multicolumn{2}{|c|}{ Ratio (\%) } \\
\hline & I & II & I & II & I & II & I & II & I & II \\
\hline 0 & 17,0 & 14,2 & 3,8 & 3,7 & $0,8 \mathrm{a}$ & 0,8 a & 9,0 & 8,9 & 10,6 a & $10,5 \mathrm{a}$ \\
\hline 100 & 15,4 & 13,2 & 3,9 & 3,7 & $0,8 \mathrm{a}$ & $0,6 \mathrm{~b}$ & 9,1 & 9,2 & $11,2 \mathrm{~b}$ & $14,3 \mathrm{a}$ \\
\hline 200 & 13,6 & 17,0 & 3,9 & 3,9 & $0,7 \mathrm{a}$ & $0,5 \mathrm{~b}$ & 9,6 & 8,4 & $12,8 \mathrm{~b}$ & $14,7 \mathrm{a}$ \\
\hline 400 & 15,9 & 15,3 & 3,8 & 3,9 & $0,7 \mathrm{a}$ & $0,6 \mathrm{~b}$ & 8,4 & 9,0 & $12,0 \mathrm{~b}$ & $14,8 \mathrm{a}$ \\
\hline CV (\%) & \multicolumn{2}{|c|}{29,76} & \multicolumn{2}{|c|}{2,80} & \multicolumn{2}{|c|}{10,11} & \multicolumn{2}{|c|}{7,0} & \multicolumn{2}{|c|}{9,21} \\
\hline
\end{tabular}

Médias não seguidas de mesma letra, na linha dentro cada variável, diferem entre si pelo teste de Tukey a 5\% de probabilidade de erro.

do incremento da capacidade de crescimento das frutas (AGUSTÍ \& ALMELA, 1991). Ao final do período de queda fisiológica, as frutas são pequenas e necessitam de grande quantidade de carboidratos para o crescimento. A competição entre elas resulta em correlação negativa entre o número de frutas por planta e seu tamanho na colheita.

Aumentos entre 5\% e 10\% no tamanho final das frutas também foram observados com a aplicação de concentrações de 50 a $75 \mathrm{mg} \mathrm{L}^{-1}$ de ethephon no final da queda fisiológica das frutas em tangerineira “Clementina” (Citrus clementina Hort. ex Tan.) (AGUSTÍ et al., 1991; VANNIERE \& ARCUSET, 1992).

Em tangor "Murcote", a aplicação do ethephon também favoreceu o aumento no diâmetro das frutas. O aumento constatado no tamanho das frutas foi atribuído à redução do número de frutas devido ao releio provocado (SERCILOTO et al., 2003).

As frutas apresentaram comportamento semelhante em relação ao número de gomos formados para os diferentes tratamentos com a aplicação das concentrações de ethephon nos dois estádios de desenvolvimento das frutas (Tabela 1). Dessa forma, considerando os efeitos dos tratamentos sobre o diâmetro transversal, conforme mostrado na tabela 1 , o aumento de $9,57 \%$ nas frutas das plantas que foram pulverizadas com a concentração de $400 \mathrm{mg} \mathrm{L}$ ${ }^{1}$ de ethephon, no estádio de dois $\mathrm{cm}$ de desenvolvimento ocorreu, provavelmente, pelo crescimento dos lóculos devido ao aumento de suco nas vesículas e não devido ao aumento do número de gomos formados.

Não foram observadas diferenças no número de sementes nas frutas da tangerineira “Ponkan” em razão da aplicação de ethephon nos estádios de desenvolvimento (Tabela 1). Esse resultado indica que a aplicação do ethephon não interfere no processo reprodutivo das plantas.

Nas plantas tratadas com as diferentes concentrações de ethephon nos dois estádios de desenvolvimento das frutas, a produção também não diferiu. Possivelmente esse resultado se deva ao aumento do diâmetro e peso das frutas nas plantas que receberam as concentrações de ethephon. Desse modo, o menor número de frutas nessas plantas não determinou redução do número de caixas de frutas colhidas, pelo fato de ser colocado menor número de frutas de tamanhos maiores por caixa. Esses resultados são contrastantes de outros autores, os quais observaram decréscimo na produção por planta com aplicação de ethephon (PACHECO 1999, SERCILOTO et al., 2003).

$\mathrm{O}$ pH avaliado no suco das frutas não foi alterado com a aplicação das concentrações de ethephon tanto nas plantas que foram pulverizadas no estádio de um $\mathrm{cm}$, quanto nas plantas no estádio de dois cm de desenvolvimento das frutas (Tabela 1). Esses resultados estão de acordo com os obtidos por SERCILOTO et al. (2003), os quais também não observaram alterações nos valores de $\mathrm{pH}$ com o raleio de tangor "Murcote" com a utilização ethephon. 
A acidez titulável das frutas da tangerineira "Ponkan” apresentou variações em função dos tratamentos. Houve redução de $27,49 \%$ na acidez do suco das frutas no estádio de um cm, e 34,1\% nas furtas das plantas que foram pulverizadas no estádio de dois cm estimado com a concentração de $400 \mathrm{mg} \mathrm{L}^{-1}$ de ethephon (Figura 1C). A redução observada neste trabalho está em desacordo com os resultados obtidos por RUFINI (2003), que não encontrou diferença da acidez avaliada nas frutas com utilização de ethephon.

Não houve diferenças nos sólidos solúveis avaliados nas frutas das plantas de tangerineira "Ponkan” devido à aplicação das diferentes concentrações de ethephon em ambos os estádios de desenvolvimento (Tabela 1). Esses resultados sugerem que o crescimento da fruta obtido com a aplicação do ethephon não altera as suas características próprias na maturação.

O efeito do ethephon alterou a relação sólidos solúveis/acidez (ratio). Embora não tenha ocorrido aumento dos teores dos sólidos solúveis, a redução no teor de acidez contribuiu para o aumento dessa relação (Figura 1D). Os maiores valores foram estimados com as concentrações de 308 e $230 \mathrm{mg} \mathrm{L}^{-1}$ de ethephon, que representaram o incremento de $41,45 \%$ e $17,76 \%$ na relação sólidos solúveis/acidez do suco das frutas, nos estádios de um e dois cm, respectivamente. As variações nos teores de sólidos solúveis e acidez que resultam no incremento ou decréscimo da ratio têm sido relatadas por diversos autores, dentre eles, SERCILOTO et al., 2003, os quais, apesar de não observarem diminuição do Brix, observaram que a redução da acidez manteve a proporção da relação sólidos solúveis/acidez (ratio).

A aplicação de ethephon na concentração de 400mg $\mathrm{L}^{-1}$, no estádio de desenvolvimento de dois cm para o raleio químico da tangerineira "Ponkan”, proporciona o melhor resultado em maior massa fresca das frutas, em comparação com a não aplicação do produto.

\section{REFERÊNCIAS}

AGUSTÍ, M. et al. Efecto del 2,4-DP sobre el desarollo y tamaño final del fruto de la mandarina 'Clementina Fina' (Citrus reticulata Blanco). Levante Agricola, Valencia, v.307/308, p.4-12, 1991.

AGUSTÍ, M. et al. Desarrollo y tamaño final del fruto en los agrios. Valência: Generalitat Valenciana, 1995. 80p.

AGUSTÍ, M.; ALMELA, V. Aplicación de fitorreguladores en citricultura. Barcelona: Aedos, 1991. 261p.

CASTRO, P.R.C. Biorreguladores em citros. Laranja, Cordeirópolis, v.22, n.2, p.367-381, 2001.
FERREIRA, D.F. Análise estatística por meio do SISVAR (Sistema para Análise de Variância) para Windows versão 4.0. In: REUNIÃO ANUAL DA REGIÃO BRASILEIRA DA SOCIEDADE INTERNACIONAL DE BIOMETRIA, 45., 2000, São Carlos. Anais... São Carlos: UFSCar, 2000. p.255258.

GUARDIOLA, J.L. Fruit set and growth. In: INTERNATIONAL SEMINAR ON CITRUS, 2., 1992, Jaboticabal. Proceedings... Jaboticabal: Funep, 1992. p.1-29.

GUARDIOLA, J.L.; GARCÍA-LUIS, A. Increase size in citrus. Thinning and stimulation of fruit growth. Plant Growth Regulation, v.31, p.121-132, 2000.

ORTOLA, A.G. et al. Fruitlet age and inflorescence characteristics affect the thinning and the increase in fruitlet growth rate induced by auxin applications in citrus. Acta Horticulturae, Wazeningen, n.463, p.501-508, 1998.

PACHECO, A.C. Desbaste químico em tangerina "Ponkan” (Citrus reticulata Blanco) com a utilização de reguladores vegetais: aspectos fisiológicos e tecnológicos. 1999. 90f. Dissertação (Mestrado em Fisiologia e Bioquímica de Plantas) - Escola Superior de Agricultura "Luiz de Queiroz”, Universidade de São Paulo, Piracicaba, SP.

RUFINI, J.C.M. Alteração da época de colheita de frutos da tangerineira "Ponkan" com a aplicação de ethephon, GA3 e 2,4D. 2003. 72f. Tese (Doutorado em Produção Vegetal) - Curso de pós-graduação em Fitotecnia, Universidade Federal Lavras, Lavras, MG.

SANCHES, F.R. Aplicação de biorreguladores vegetais: aspectos fisiológicos e aplicações práticas na citricultura mundial. Jaboticabal: Funep, 2000. 160p.

SANTOS, A.C.P.; CASTRO, P.R.C. Desbaste químico em tangerineira 'Ponkan' sobre o nível de carboidratos e a composição mineral das folhas. Laranja, Cordeirópolis, v.22, n.1, p.93-112, 2001.

SERCILOTO, C.M.; CASTRO, P.R.C. Uso de biorreguladores em lima ácida 'Tahiti'. Laranja, Cordeirópolis, v.22, n.2, p.383-394. 2001.

SERCILOTO, C.M. et.al. Desbaste e desenvolvimento do tangor 'Murcote' com o uso de biorreguladores. Laranja, Cordeirópolis, v.24, n.1, p.95-111, 2003.

SHARMA, R.K.; AWASTHI, R.P. Effects of growth regulators on crop regulation of Kinnow (Citrus nobilis $x$ citrus deliciosa). Indian Journal of Horticulture, Amsterdam, v.47, p.162166, 1990.

SUZUKI, K. et al. The effects of mixing ethephon with ethylchlosate on fruit thinning and defoliation in satsuma mandarin (Citrus unshiu Marcovitch). Bulletin of the Fruit Tree Research Station, Japan, v.17, p.45-54, 1990.

VANNIERE, H. ARCUSET, P. Fruit size improvement in 'Common Clementine' mandarin by using dichlorprop. Proceedings of the International Society of Citriculture, Italy, v.1, p.524-526, 1992. 